\title{
Perceptions of transformational leadership and job satisfaction: The roles of personality traits and psychological empowerment ${ }^{\S}$
}

\author{
Ceren Aydogmus, ${ }^{\star}$ Selin Metin Camgoz ${ }^{\star \star}$ Azize Ergeneli** and Ozge Tayfur Ekmekcl ${ }^{\star \star}$
}

\begin{abstract}
Through two studies, this paper investigates the moderating effects of personality traits (i.e., extraversion, conscientiousness, agreeableness and neuroticism) and the mediating effect of psychological empowerment on the relationship between perceived transformational leadership and job satisfaction. Study 1 searches whether personality traits moderate the effects of perceived transformational leadership on followers' job satisfaction. Using a sample of $221 \mathrm{R} \& \mathrm{D}$ employees employed by information technology organizations, the results of Study 1 indicate that the more conscientious the employee, the stronger the relationship between perceived transformational leadership and job satisfaction. Study 2 explores whether psychological empowerment mediates the effects of perceived transformational leadership on followers' job satisfaction. Based on data from 348 academics, the results support the mediating role of psychological empowerment on job satisfaction, in that when employees perceive their leader as transformational they feel more psychologically empowered, which in turn increases job satisfaction levels. Implications for future research and practice are discussed.
\end{abstract}

Keywords: perceived transformational leadership, personality traits, psychological empowerment, job satisfaction

Received 1 February 2016. Accepted 6 November 2016

$\mathrm{T}$ oday's dynamic work environment brought about by economic, technological and demographic changes affecting the magnitude of employee job satisfaction. It has been well documented that highly satisfied employees are more likely to be committed to their organization (Cooper-Hakim \& Viswesvaran, 2005), have higher levels of job performance (Judge, Scott, \& Ilies, 2006) and lower levels of turnover (Hulin \& Judge, 2003). The accumulating evidence about the role of job satisfaction on various organizational outcomes triggered the studies investigating its predictors. Although job satisfaction was found to be affected by situational factors, it was also found to be shaped by individual

* Faculty of Business Administration, Bilkent University, Ankara, Turkey

** Department of Business Administration, Faculty of Economics and Administrative Science, Hacettepe University, Ankara, Turkey

$\S$ This manuscript is an original work that has not been submitted to nor published anywhere else. This study probes the underlying mechanism and the processes of how followers' perceptions of transformational leadership influence job satisfaction, with a focus on followers' personality traits and psychological empowerment with two different studies. With this aim, we provide follower-based perspective on leadership issues on management and organizations of benefit to scholars, Human Resource practitioners and managers.

Corresponding author: caydogmus@bilkent.edu.tr 
factors such as dispositions (Templer, 2012) and perceptions. Among these individual factors, followers' perceptions of transformational leadership (Cicero \& Pierro, 2007) and followers' personality traits (Judge, Heller, \& Mount, 2002; Hsieh, 2013) have arisen as important predictors.

Transformational leadership is most commonly defined as a set of behaviours, which transforms followers' needs by satisfying self-actualization needs and push their own and employers' expectations to higher levels (Bass \& Avolio, 1994). Transformational is based on the premise that such leadership encourages employee development and increases followers' motivation levels and morale (Burns, 1978). The research on transformational leadership has been predominantly leader centred, yet scholars have recently realized that followers remain an unexplored source of variance in the leadership process. Thereby, researchers have begun to take a more follower-centred perspective, emphasizing the role of followers in an interactive leadership process (Gardner \& Avolio, 1998; Ozaralli, 2003; Hetland, Sandal, \& Johnsen, 2008; Gumusluoglu \& Ilsev, 2009; Braun, Peus, Weisweiler, \& Frey, 2013; Qu, Janssen, \& Shi, 2015). In contrast to the leader-centred perspective, scholars of the follower-centred perspective argue that becoming and remaining an effective leader does not only depend on the leader's actual behaviour, but also on followers' attributions, perceptions and characteristics.

Accumulating evidence confirms the direct relationship between employees' transformational leadership perceptions regarding their supervisors and job satisfaction (Bass, 1999; Krishnan, 2012), however, studies on the moderating effects between perceived transformational leadership and job satisfaction are relatively rare and mostly neglect individual differences.

The present research aims to examine the processes by which followers' perceptions of their leaders as more transformational precipitate their influence on job satisfaction. The purpose of this article is to extend the association between perceived transformational leadership and job satisfaction by adding to the body of work on the follower-centred leadership perspective. With this aim, Study 1 investigates the moderating effects of four personality traits (extraversion, conscientiousness, agreeableness and neuroticism) on the relationship between perceived transformational leadership and job satisfaction. Specifically, we assume that the effect of perceived transformational leadership on job satisfaction varies as a function of followers' personality traits. We posit that follower's perceptions of their leaders as transformational might interact with follower's personality traits, and that this interaction contributes positively or negatively to job satisfaction. Understanding the moderating effects of followers' personality traits associated with their transformational leadership perceptions may help to better understand the dispositional predictors of job satisfaction. Clearly, these findings may have important organizational implications, including for selection and human resources training and development.

Through focussing on followers, in Study 2, we examine the underlying mechanism and processes of how their perceptions of transformational leadership influence job satisfaction, with a focus on psychological empowerment. This concept is defined as the intrinsic task motivation manifested in cognitions that reflect an individual's active orientation to his or her work role' (Spreitzer, 1995: 1443). Several studies report that transformational leaders empower their followers (Jung \& Sosik, 2002; Joo \& Lim, 2013; Dust, Resick, \& Mawritz, 2014; Pai \& Krishnan, 2015). While research on perceived transformational leadership with job satisfaction has flourished, the effects of empowerment among followers have been virtually ignored. In line with the transformational leadership theory emphasizing the role of empowerment as a central mechanism (Avolio, Zhu, Koh, \& Bhatia, 2004) we explore psychological empowerment as the mediating variable in perceived transformational leadership and job satisfaction linkage. We argue that followers' perceptions of their leaders as transformational affect their psychological empowerment levels and thus in turn contribute to their job satisfaction.

Before discussing the theoretical framework for the hypotheses of the study, it seems necessary to give information about the cultural values and business context in Turkey, given the fact that such information would provide more complete picture regarding the transformational leadership and its 
effects in organizations. Therefore, in the preceding sections, first information about Turkish culture and business environment; then theoretical rationale for hypotheses will be discussed.

\section{CULTURAL VALUES AND BUSINESS CONTEXT IN TURKEY}

Turkish culture is argued to be a blend of 'Western' and 'Eastern' values (Aycan, 2001), probably due to Turkey's historical ties and geographic location connecting Asia and Europe. In early studies, Turkish culture was found to have high power distance and collectivistic tendencies (Hofstede, 1980), which are peculiar to Eastern societies and their value systems. However, Turkish culture has been transformed like many other societies. Autonomy and self-determination have aroused as basic values in Turkish families (Kagitcibasi, 1996), which cause changes in power distance and collectivist tendencies. In fact, recent studies show that Turkey has become less collectivistic (Goregenli, 1997; Aycan et al., 2000; Fikret-Pasa, Kabasakal, \& Bodur, 2001) and less hierarchical (Aycan et al., 2000) compared with past. The transformation in the societal values has reflected itself in Turkish organizations as well. After the adoption of liberal economy in 1980s, the organization structures in Turkey have become less hierarchical (Aycan et al., 2000) with less uncertainty avoiding (Kabasakal \& Bodur, 1998).

Despite the adoption of some Western values, still Turkish societal and organizational culture are characterized with collectivism and power distance, which shape leader-follower relations to a large extent. Studies investigating the leadership styles in Turkey reported that Turkish managers show parental consideration towards their subordinates (e.g., Aycan \& Fikret-Pasa, 2003), and exhibit nurturing and authoritarian behaviours at the same time. In this paternalistic leadership style, supervisors assume the role of a parent and consider it an obligation to provide support and protection to those under their care (Aycan and Kanungo, 2000). Subordinates, in turn, reciprocate such care, support and protection of the paternal authority by showing loyalty, trust and respect to their supervisors. Turkish employees/subordinates are looking for leaders who are basically relationship oriented (i.e., showing individualized attention to followers), display concern with the private problems of followers and create an intimate atmosphere in the organization (Fikret-Pasa, Kabasakal, \& Bodur, 2001). Besides paternalistic leadership, these behaviours are compatible with the dimensions of transformational leadership. In fact, recent studies reported that transformational leadership is the most preferred leadership style in Turkey (Aycan \& Fikret-Pasa, 2003; Gumusluoglu \& Ilsev, 2009; Gumusluoglu, Karakitapoğlu-Aygün, $\&$ Hirst, 2013). As in other countries, much of the interest has been devoted to investigate the prevalent and preferred leadership styles in Turkey; however, less attention has been directed to the investigation of how these leadership styles affect employee's perceptions such as perceived empowerment and job satisfaction. This study could provide insights about how transformational leadership influences the perceived empowerment and job satisfaction in Turkey, which is argued to differ from both Western and Eastern societies in terms of some societal values.

\section{THEORETICAL BACKGROUND AND HYPOTHESES DEVELOPMENT}

\section{Transformational leadership and job satisfaction}

Job satisfaction is the pleasurable emotional state that results from the appraisal of one's job as achieving or facilitating one's job values (Locke, 1969). It is the evaluation of an individual's own work in terms of the context and content of the work. Among many determinants of job satisfaction, an employee's direct manager or leader has the greatest influence on whether an employee finds his or her job satisfying or not (Avolio, Bass, \& Jung, 1999; Mardanov, Heischmidt, \& Henson, 2008). Among various leadership styles, recent work suggests that transformational leadership (Bass, 1985) has a more favourable impact on employee job satisfaction compared with other leadership approaches (Awamleh \& Gardner, 1999; 
Bogler, 2001; Cicero \& Pierro, 2007; Top, Tarcan, Tekingündüz, \& Hikmet, 2013; Ghanbari \& Eskandari, 2014; Çoğaltay, Yalcin, \& Karadağ, 2016). Scholars regard transformational leadership as a tool to enhance follower satisfaction by encouraging employee development, interaction and promoting motivation (Avolio, 1999). Transformational leadership fosters autonomy and encourages challenging work, thus becoming increasingly important to followers' job satisfaction (Bass, 1999).

Transformational leadership consists of four interrelated behavioural components of idealized influence: (1) charismatic role modelling, (2) inspirational motivation that articulates an appealing vision, (3) individualized consideration and (4) intellectual stimulation that promotes creativity and innovation (Bass \& Avolio, 1994). The related literature demonstrates that dimensions of transformational leadership have positive effects on job satisfaction (Judge \& Bono, 2000; Krishnan, 2012). Particularly, intellectual stimulation leads employees to see their work as more interesting due to increased self-understanding and growth (Jung \& Sosik, 2002). Leader charisma generates loyalty and appreciation from followers (Bass \& Avolio, 1994) and inspirational motivation leads employees to feel involved in their tasks and understand the vision of the organization (Kerfoot, 2001). Individualized consideration involves caring management through personal attention and treatment (Slater, 2003). From these factors, we expect that when a follower perceives his or her leader as more transformational, he or she will feel higher job satisfaction. Therefore

Hypothesis 1: Perceived transformational leadership is positively correlated with job satisfaction.

\section{Moderating roles of followers' personality traits (Study 1)}

Although the relationships between perceived transformational leadership and job satisfaction have been clearly demonstrated (Judge \& Bono, 2000; Krishnan, 2012), the potential moderating effects of individual differences remain largely inconclusive. Some scholars examining individual differences (Monzani, Ripoll, \& Silla, 2014) argue that those differences serve as situational moderators for transformational leadership effectiveness (Wofford, Whittington, \& Goodwin, 2001). This argument has also been supported by Lord, DeVader, and Alliger (1986), suggesting that cognitive schemas composed of personality traits are important perceptual constructs that predict leadership perceptions. In this sense, Bass (1999) and Conger and Kanungo (1998) note that transformational leadership might be more effective for some followers than for others, thereby suggesting that follower characteristics could be important moderators on the effects of such leadership on followers' job attitudes, including job satisfaction. If followers' characteristics play an important role in transformational leadership perception, these characteristics should explain the variance of perceived transformational leadership in addition to the variance of followers' job satisfaction. Consistent with other situational approaches to leadership, we presume that followers' personality traits moderate the relationships between followers' perceptions of their leaders as transformational and their job satisfaction. In discussing the proposed moderating hypotheses, we utilize and define personality in terms of the Big-Five personality traits excluding openness to experience (i.e., extraversion, conscientiousness, agreeableness and neuroticism) in line with prior studies. The traits are widely recognized and have been found to be related to many organizational attitudes and outcomes, including job satisfaction (Judge, Heller, \& Mount, 2002). However, openness to experience was found to have weak correlations with job satisfaction (Judge, Heller, \& Mount, 2002). DeNeve and Cooper (1998) discovered the effect of openness to experience on job satisfaction was unclear. Nevertheless, there are contradictory findings about the relationship between followers' openness and their perceptions for transformational leadership. Although some findings (Moss \& Ngu, 2006) suggest that there is a positive, some identify (Hetland, Sandal, \& Johnsen, 2008) no correlation on this relationship. Therefore, openness to experience will not be investigated in this study. 
Within the Big-Five personality model, extraversion is associated with being social, assertive, expressive, energetic, talkative and active (Goldberg, 1990). As extraversion correlates with pleasant emotions (Lucas, Diener, Grob, Suh, \& Shao, 2000), extraverted individuals experience more positive affective reactions compared with introverts (Rusting \& Larsen, 1997) when faced with the same pleasant events. Recent research suggests that higher extraversion scores are positively correlated with all components of job satisfaction (Judge, Heller, \& Mount, 2002). Put differently, employees who are high in extraversion perceive their working environment more positively (Weiss \& Cropanzano, 1996) which in turn generalizes to job satisfaction (Judge, Heller, \& Mount, 2002).

In terms of leadership practices, extraversion might play an important role in shaping individuals' perceptions of leadership preferences (Keller, 1999). Felfe and Schyns (2006) assert that extraversion in particular is positively related to the perception and acceptance of transformational leadership, finding that followers high in extraversion have a tendency to perceive their leaders as more transformational than do followers low in extraversion. Similarly, leaders may be more encouraged to activate a transformational style when encountering followers with high levels of social activity and initiative, as they will perceive their followers as having the appropriate characteristics for such leadership (Dvir \& Shamir, 2003). As individuals high in extraversion tend to place more emphasis on transformational leadership practices, one might presume that the relationship between perceived transformational leadership and job satisfaction becomes stronger. Thus

Hypothesis 2: Followers' extraversion moderates the relation between perceived transformational leadership and job satisfaction such that the effect of the former on the latter will be stronger when followers are high in extraversion.

Conscientiousness involves being responsible, organized, dependable, careful and hardworking. Considerable research proves that none of the Big-Five personality traits except conscientiousness predicts global and subscale scores of actual job satisfaction (Winkelmann \& Winkelmann, 2008; Furnham, Eracleous, \& Chamorro-Premuzic, 2009). Likewise, the findings of meta-analyses aggregating over different samples in different countries with different outcome criteria display that conscientiousness is most likely the best predictor of work-related behaviour (Salgado, 1997). Put differently, individuals who are high in conscientiousness are better-performing employees; they receive more rewards and recognition, which in turn increases their job satisfaction (Templer, 2012). A potential explanation for this finding might be that as conscientious individuals are more likely to receive higher intrinsic and extrinsic rewards due to their efficient nature that might consequently increase their levels of job satisfaction (Furnham, Eracleous, \& Chamorro-Premuzic, 2009).

In terms of leadership practices, research shows that the more conscientious the followers, the more they are recognized and the more they react positively to transformational leadership, leading to higher ratings of transformational leadership behaviour (Bono, Hooper, \& Yoon, 2012). Leaders may also be encouraged to activate a transformational leadership style while working with high self-esteem and conscientious followers (Dvir \& Shamir, 2003). Ehrhart and Klein (2001) find that followers' achievement orientation and high self-esteem, which are the main features of conscientiousness, are positively related to the preference of a transformational leader. Additionally, it has been defined that conscientiousness implies a positive attitude towards the work and the leader (Hetland, Sandal, \& Johnsen, 2008). Keller (1999) finds that conscientious followers are more likely to notice and recall transformational leadership behaviours because they view charisma and dedication as ideal leader characteristics. Additionally, as conscientious followers are very good performers, leaders may appreciate them more than other followers and place relatively more importance on their development needs, such as individualized consideration (Hurtz \& Donovan, 2000). Consequently, leaders may think conscientious followers are worth the investment in terms of productivity and may be more likely to respond to the needs of these followers (Bono, Hooper, \& Yoon, 2012). Leaders have a tendency to 
activate a transformational style when they work with employees having high levels of responsibility, social activity and self-esteem (Walumbwa, Orwa, Wang, \& Lawler, 2005). Hence, as followers high in conscientiousness have a tendency to place more emphasis on transformational leadership practices, we hypothesize that the relationship between perceived transformational leadership and job satisfaction becomes stronger. Thus

Hypothesis 3: Followers' conscientiousness moderates the relation between perceived transformational leadership and job satisfaction such that the effect of the former on the latter will be stronger when followers are high in conscientiousness.

Agreeableness refers to being friendly, good natured, trusting, cooperative, forgiving and tolerant. McCrae and Costa (1991) identified that agreeable individuals have greater motivation to achieve interpersonal relationships. As agreeableness involves getting along with others in pleasant and satisfying relationships, it is positively correlated with job satisfaction (Organ \& Lingl, 1995). Tasks can be perceived as more distressing and cause less job satisfaction for followers with low agreeableness (Christiansen, Sliter, \& Frost, 2014). Related to leadership practices, agreeableness is found to be a strong predictor of transformational leadership preference (Parmer, Green, Duncan, \& Zarate, 2013). Research suggests that followers with high agreeableness perceive their leaders as more transformational (Felfe \& Schyns, 2010) and followers low in agreeableness are less open to transformational leadership behaviours (Hetland, Sandal, \& Johnsen, 2008). Further, Hetland and Sandal (2003) posit that agreeableness has the strongest correlation to both transformational leadership and job satisfaction because it includes warmth. Therefore, we hypothesize that the relationship between perceived transformational leadership and job satisfaction will become stronger when followers are high in agreeableness. Thus

Hypothesis 4: Followers' agreeableness moderates the relation between perceived transformational leadership and job satisfaction such that the effect of the former on the latter will be stronger when followers are high in agreeableness.

The last personality trait, neuroticism, includes being depressed, anxious, angry, embarrassed, emotional, worried and insecure. It is the strongest and most consistent negative correlate of job satisfaction (Judge, Heller, \& Mount, 2002). Individuals high in neuroticism generally view the world from a negative aspect, and they self-select into situations that foster negative influence. They are emotionally unstable, become easily upset and habitually experience negative emotions. Neurotic employees therefore have fewer fulfilling and rewarding interactions at work, which might lead them to feel lower job satisfaction than emotionally stable employees (Connolly \& Viswesvaran, 2000). Indeed, research shows that employees high in neuroticism have relatively lower job satisfaction (Spector, 1997; Templer, 2012).

Regarding leadership preferences, research also suggests that followers with high neuroticism perceive their leaders as less transformational (Hetland, Sandal, \& Johnsen, 2008; Bodla \& Hussain, 2010). As neuroticism indicates lower self-esteem and higher anxiety, neurotic followers may withdraw when confronted with a transformational leader (Felfe \& Schyns, 2010). As neurotic employees view the world from a negative lens, they are not fully aware of the behaviours and attitudes of their superiors towards them, such as individual consideration and inspirational motivation (McCrae \& Costa, 1997). In other words, the more neurotic the follower, the more negative the relationship between perceived transformational leadership and job satisfaction. Thus, we hypothesize

Hypothesis 5: Followers' neuroticism moderates the relation between perceived transformational leadership and job satisfaction such that the effect of the former on the latter will be weaker when followers are high in neuroticism. 


\section{The mediating role of psychological empowerment (Study 2)}

Psychological empowerment refers to a set of psychological states that are necessary for individuals to feel a sense of control in relation to their work. Spreitzer (1995) suggests four cognitions of psychological empowerment: (1) meaning, the value of work goals judged in relation to an individual's own ideas, (2) competence (self-efficacy), an individual's belief in his or her capability to perform activities with skill, (3) determination, the reflection of autonomy in the initiation and continuation of work processes and (4) impact, the degree to which an individual can influence strategic, administrative or operating work outcomes (Thomas \& Velthouse, 1990). These four perceived empowerment cognitions combine additively to create an overall construct of psychological empowerment.

It is well known that transformational leadership is increasingly encouraged to facilitate job satisfaction. Although the associations between transformational leadership and job satisfaction have been well reported (Awamleh \& Gardner, 1999; Bogler, 2001) underlying processes among those relationships are inconclusive. As psychological empowerment is argued to be one of the main features distinguishing transformational leadership behaviours from other leadership styles (Kark, Shamir, \& Chen, 2003), we believe that it acts as an important psychological mechanism to mediate the relationship between perceived and job satisfaction.

Research shows that transformational leadership is positively related to psychological empowerment (Judge \& Bono, 2000; Ozaralli, 2003; Castro, Villegas, \& Casillas, 2008) suggesting that psychological empowerment involves the delegation of responsibility to followers and the enhancement of their capacity to think for themselves in producing new and creative ideas (Spreitzer, 1995). Thus, the nature of transformational leadership in developing followers' self-management and self-development skills relates to the notion of follower perceptions of empowerment (Jung, Chow, \& Wu, 2003). In this regard, one might propose that transformational leadership facets act through psychological empowerment in influencing work outcomes (Bass, 1999).

Moreover, transformational leaders emphasize the independence and proactivity of their followers, and favour empowerment strategies rather than control (Dvir \& Shamir, 2003). Such leaders empower followers by generating enthusiasm for achieving a goal and by providing meaning (Bass, 1999). In addition, such leaders favour psychological empowerment cognitions by expressing confidence in employee ability to deliver high performance (Conger, Kanungo, \& Menon, 2000). Such inspirational motivation enhances followers' feelings of self-efficacy and perceived competence (Spreitzer, 1995). Transformational leaders use intellectual stimulation to challenge their followers' imagination and creativity, which could result in this sense of self-determination (Castro, Villegas, \& Casillas, 2008).

Numerous studies have concluded that job satisfaction is a consequence of psychological empowerment, as it is associated with perceptions of control and competence, increased autonomy and working on an idea that is personally appealing and meaningful (Eylon \& Bamberger, 2000). Individualized consideration for followers' need for achievement and growth can encourage them to take on challenging responsibilities to develop their full potential, thus keeping them on track for cognitive states of empowerment (Avolio et al., 2004). Likewise, empowering followers by providing them autonomy to manage their work and by increasing its perceived meaning facilitates work-related learning and thereby improves job satisfaction (Bartram \& Casimir, 2006). Thus, it is plausible to expect that when followers perceive their leaders as more transformational, such a perception would positively influence their psychological empowerment, which would result in higher job satisfaction. To summarize, previous research supports (1) links between perceived transformational leadership and job satisfaction, (2) the association between psychological empowerment and job satisfaction. However, to the authors' knowledge there has been no research until now exploring whether this relationship is mediated through psychological empowerment. It might be that perceived 


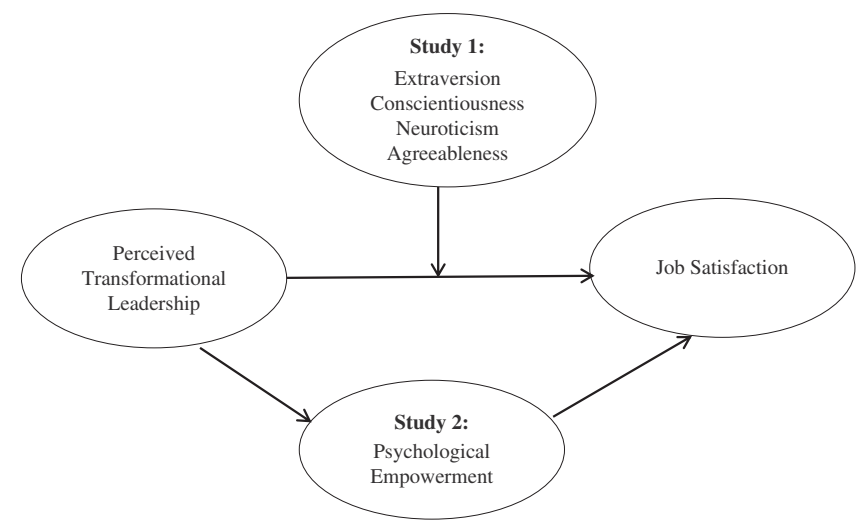

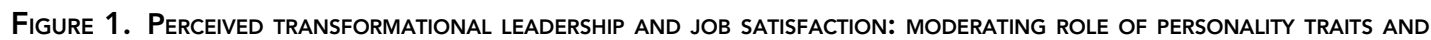
MEDIATING ROLE OF PSYCHOLOGICAL EMPOWERMENT

transformational leadership is primarily related to the individual's evaluation of empowerment and that this strong sense of empowerment might contribute to higher levels of job satisfaction. Therefore

Hypothesis 6: The effects of followers' perceived transformational leadership on job satisfaction will be mediated by psychological empowerment.

The conceptual/theoretical framework of the mediating relationships between perceived transformational leadership, psychological empowerment and job satisfaction is summarized in Figure 1.

\section{STUDY 1 METHOD}

\section{Participants}

The data from Study 1 consists of 221 white-collar employees working in R\&D at various information technology companies located at three universities. All companies are small or medium sized, with 20-50 employees, and all are engaged in developing new products and improving existing products. Small- and medium-sized entrepreneurial companies were chosen rather than large ones because the former may be more innovative due to their greater flexibility and thus employ more growth-oriented employees (Ettlie, 1983). Moreover, the reason for choosing the information technology sector is that employees there are more likely to perform continuous developments and respond to the new skills and demands generated by a rapidly changing and globalized labour market, in which innovation is inevitable. As transformational leadership is also positively related with innovation in the workplace (Jung, Chow, \& Wu, 2003), the aforementioned characteristics also reinforce displaying transformational types of leadership behaviours and attitudes in the organizations, which in turn makes them suitable environments for both the feeling of psychological empowerment from the follower side and the development of transformational leaders from the organizational side. Among the participants, 55\% were male and 45\% female. Almost half had worked with their current manager for up to 3 years at the time of the study. The average job tenure was $6.8(\mathrm{SD}=0.91)$ and the mean age of the participants was $38.6(\mathrm{SD}=4.12)$.

\section{Measures}

The self-reported survey for Study 1 included measures of transformational leadership, Big-Five personality traits and job satisfaction. The responses to all of the following multi-item scales were averaged to form composite variables. 


\section{Multifactor Leadership Questionnaire}

Followers' perceptions of transformational leadership were assessed with 20 items taken from the Multifactor Leadership Questionnaire (Form 5X-Short) (Bass \& Avolio, 1995). Participants were asked to rate their supervisor's leadership behaviours using a 5-point Likert scale format, ranging from $1=$ 'not at all,' to $5=$ 'frequently'. Sample items include the following: 'display a sense of power and confidence' for idealized attribute; 'consider the moral and ethical consequences of decisions' for idealized behaviour; 'talk optimistically about the future' for inspirational motivation; 'seek differing perspectives when solving problems' for intellectual stimulation and 'spend time teaching and coaching' for individual consideration. In this study, rather than four dimensions, an overall measure of transformational leadership was used in all analyses for several reasons. First, the independence of transformational leadership dimensions has been a topic of some debate (Tepper \& Percy, 1994; Bycio, Hackett, \& Allen, 1995; Avolio, Bass, \& Jung, 1999). In the prior studies, high correlations were reported among the four transformational leadership dimensions (Lowe, Kroeck, \& Sivasubramaniam, 1996). Second, both theoretical (Bass, 1990; Yukl, 1994) and empirical studies (Yammarino, Dubinsky, Comer, \& Jolson, 1997) suggest that an overall measure is a valid and reliable approach. The items were translated into Turkish using a collaborative translation technique in order to ensure their conceptual equivalence. Two bilingual researchers translated the scale independently and one graduate psychology student examined which translation better reflected the items' meanings. No analogous items were identified, and as a result, the comparability of the translations was assumed. The Cronbach's $\alpha$ coefficient was 0.94 .

\section{Big-Five Inventory (BFI)}

The 44-item BFI developed by John, Donahue, and Kentle (1991) was used to assess participants' personality traits. Respondents rated each item on a 5-point scale ranging from 1 = 'disagree strongly,' to 5 = 'agree strongly', based on how much each statement described him or her. Sample items are as follows: 'is outgoing/ talkative' for extraversion; 'perseveres until the task is finished/does a thorough job' for conscientiousness; 'likes to cooperate with others/is generally trusting' for agreeableness; and 'gets nervous easily/worries a lot' for neuroticism. The Turkish translation and adaptation of the instrument was conducted by Sumer, Lajunen, and Ozkan (2005). $\alpha$ coefficients for each of the BFI subscales were all at reasonable intervals, ranging from 0.72 to 0.86 .

\section{Job satisfaction}

A 20-item short form of the Minnesota Satisfaction Questionnaire designed by Weiss, Dawis, England, and Lofquist (1967) was used to assess employees' overall job satisfaction. Sample items include 'the working conditions' and 'the way my boss handles his/her workers'. Each item generated responses ranging from 'very dissatisfied' (1) to 'satisfied' (5) on a 5-point scale. The Turkish adaptation and the validity of the Turkish version of the instrument have been established by Bilgic (1998). Cronbach's $\alpha$ coefficient was found to be 0.85 .

\section{Procedure}

The study questionnaires were administered by one of the researchers in an on-site meeting room during regular scheduled working hours. All participants gave consent after being informed that the study aimed to investigate several aspects of their work life and that they were assured anonymity and confidentiality. No incentives were offered. In total, 221 useable questionnaires were returned out of 300 distributed ones, a response rate of $73.6 \%$. 


\section{Common method bias}

As the data were collected from a single source, to diminish common method variance, we (1) used different response anchors for the predictor and outcome variables, (2) manipulated the order of the questionnaire items and (3) used Harman's single-factor test. With Harman's test, we put all the study variables into an exploratory factor analysis and then examined the unrotated factor solution to determine the number of factors that accounted for the variance in the variables (Podsakoff, MacKenzie, Lee, \& Podsakoff, 2003). For the present study, principal component analysis extracted 10 factors, with the first factor explaining $28.4 \%$ of the variance. This gives confidence that no single factor accounted for a majority of the covariance and no general factor was apparent, suggesting that common method variance is not a serious issue in this study (Podsakoff \& Organ, 1986). To confirm the result of Harman test, we controlled for the effects of an unmeasured latent methods factor following the suggestion of Podsakoff et al. (2003). This technique involves adding a first-order factor with all of the measures as indicators to our theoretical model. Although the addition of common method variable improved the model, this improvement was not statistically significant $\left(\Delta \chi^{2}\right.$ $(d f=1,136)=110.95 ; p>.05)$. Besides, when the significance of the structural parameters is examined both with and without the latent common methods variance factor in the model, all of the standardized loadings turned out to be significant even after the addition of common method factor. Therefore, in line with Harman's single factor test, the results of common-factor modelling analysis suggested that common method variance is not a pervasive problem in this study.

\section{STUDY 1 RESULTS}

\section{Confirmatory factor analysis (CFA)}

We performed a series of CFA to verify the distinctiveness of the constructs (i.e., study variables) in this study. However, before conducting CFA, we screened the data for accuracy and normality. For normality assumptions, outliers and univariate distributions were scanned for skewness and kurtosis scores, and found to be within reasonable ranges (skewness $<2$; kurtosis values $<2$ ). In addition, we inspected multivariate normality with Mardia's coefficient of the value of kurtosis. No violation for multivariate normality was found in the data. After this initial data screening, we compared four measurement models to check the discriminant validity of the study variables. As shown in Table 1, all of the study variables were assumed to be independent in the seven-factor model. In the three-factor model, five personality factors were combined into one factor; in the second-factor model, five personality factors and other two variables (i.e., job satisfaction and perceived transformational leadership) and lastly in the one-factor model, all variables were bound into one overall factor. As it can be seen from model fit indices in

TABLE 1. COMPARISON OF MEASUREMENT MODELS FOR MAIN VARIABLES

\begin{tabular}{|c|c|c|c|c|c|}
\hline Models & Factors & $\chi^{2} / d f$ & $C F I$ & RMSEA & $A I C$ \\
\hline 7 factor & $\mathrm{PTL}, \mathrm{JS}, \mathrm{Ext}, \mathrm{Cons}, \mathrm{Agr}, \mathrm{Ne}, \mathrm{OE}$ & 1.94 & 0.940 & 0.07 & $6,935.84$ \\
\hline 3 factor & $\mathrm{PTL}, \mathrm{JS}, \mathrm{Ext}+\mathrm{Cons}+\mathrm{Agr}+\mathrm{Ne}+\mathrm{OE}$ & 2.27 & 0.81 & 0.08 & $8,055.81$ \\
\hline 2 factor & $\mathrm{PTL}+\mathrm{JS}, \mathrm{Ext}+$ Cons $+\mathrm{Agr}+\mathrm{Ne}+\mathrm{OE}$ & 2.38 & 0.76 & 0.08 & $8,447.51$ \\
\hline 1 factor & $\mathrm{PTL}+\mathrm{JS}+\mathrm{Ext}+\mathrm{Cons}+\mathrm{Agr}+\mathrm{Ne}+\mathrm{OE}$ & 2.64 & 0.66 & 0.09 & $9,319.52$ \\
\hline
\end{tabular}

Note. Agr = agreeableness; $\mathrm{AIC}=$ Akaike information criterion; $\mathrm{CFI}=$ comparative fit index; Cons = conscientiousness; Ext = extroversion; JS = job satisfaction; $\mathrm{Ne}=$ neuroticism; $\mathrm{OE}=$ openness to experience; $\mathrm{PTL}=$ perceived transformational leadership; RMSEA = root mean square error of approximation. 
Table 1, three-, two- and one-factor models exhibited poorer fit than the seven-factor model. Besides, the Akaike information criterion used to compare alternative models, was found to be smaller in seven-factor model compared with alternative models. Overall, CFA revealed that the variance among different variables was not same, suggesting the existence of discriminant validity.

Although it was found to be superior to other models in terms of several fit indices, seven-factor model did not initially provide a good fit to the data $\left(\chi^{2}[3,390]=6,475.2 ; p<.001 ; \chi^{2} / d f=1.94\right.$; comparative fit index $[\mathrm{CFI}]=0.89$; root mean square error of approximation $[\mathrm{RMSEA}]=0.07)$. The inspection of standardized factor loadings of the BFI items revealed that three out of 44 (one for extraversion, one for openness to experience and one for neuroticism) were below the criterion of 0.40 , and so we decided to delete these items from the model. Additionally, based on modification indices, we determined that the model fit improved substantially $\left(\chi^{2}[3,381]=6,357.8 ; p<.001\right.$, where $\chi^{2} / d f=1.88$; CFI $=0.91$, and RMSEA $\left.=0.07\right)$ if the error covariance terms were added to some items of job satisfaction (i.e., between job satisfaction items 8 and 10; between items 15 and 16) and perceived transformational leadership (between items 5 and 6). After the aforementioned modifications, standardized factor loadings were examined and all of them found to be significant. We created the composite scores of the study variables by taking the average of the items shown to be statistically related to these study variables in CFA. However, because of the reasons cited in the literature review, we did not calculate composite score for openness to experience construct.

\section{Descriptive statistics}

Table 2 lists the means, standard deviations, correlations and Cronbach's $\alpha$ reliability coefficients for the variables. The correlations between variables provide initial support for the hypotheses, such that perceived transformational leadership is positively correlated with job satisfaction $(r=0.505, p<.01)$. Among the personality traits, job satisfaction is positively correlated with conscientiousness $(r=0.210$, $p<.01)$ and negatively correlated with neuroticism $(r=-0.140, p<.05)$. As the demographic variables did not significantly correlate with the outcome variable of, we did not use them as control variables.

\section{Hypotheses testing for moderating effects of personality traits}

For testing the moderating effects of the personality traits on transformational leadership-job satisfaction linkage, we conducted moderated multiple regression analysis with job satisfaction as the dependent variable, perceived transformational leadership as the independent variable and the four personality traits as the moderators. Consistent with the recommendations of Cohen, Cohen, West, and Aiken (2003), we mean centred the independent variable and the moderator variables just before computing the interaction term in order to reduce the multicollinearity problem. In the first step of the hierarchical regression analysis, we entered the independent variable and the moderator to the regression equation, whereas we added the interaction terms to the model in the second step. Table 3 provides the hierarchical regression findings where moderation is probed.

As evident in Table 3, perceived transformational leadership and personality traits accounted for $30 \%$ of the variance in job satisfaction $(F(5,216)=18.54 ; p<.001)$. Among the direct effects, the $\beta$ coefficients for transformational leadership $(\beta=0.351, p<.01)$, conscientiousness $(\beta=0.181$, $p<.05)$ and neuroticism $(\beta=-0.135, p<.01)$ were significant. The second step of the regression model was also significant, and the set of transformational leadership $\times$ personality product terms explained a significant incremental variance in job satisfaction $\left(F(9,211)=11.74 ; p<.001 ; \Delta R^{2}=\right.$ 0.032). Among the direct effects perceived transformational leadership $(\beta=0.516, p<.01)$, conscientiousness $(\beta=0.150, p<.05)$ and neuroticism $(\beta=-0.150, p<.05)$ were significant. The finding regarding the direct effect of perceived transformational leadership on job satisfaction supports Hypothesis 1. Among the interaction terms, the term between transformational 
Table 2. Descriptive statistics, $\alpha$ coefficients and correlations among Study 1 variables

\begin{tabular}{|c|c|c|c|c|c|c|c|c|c|c|c|c|}
\hline Variables & Mean & $S D$ & 1 & 2 & 3 & 4 & 5 & 6 & 7 & 8 & 9 & 10 \\
\hline 1. Gender & - & & - & -0.06 & & & & & & & & \\
\hline 2. Age & 38.60 & 4.10 & -0.06 & - & & & & & & & & \\
\hline 3. Job tenure & 6.80 & 0.90 & $-0.28 *$ & 0.62 & - & & & & & & & \\
\hline 4. Tenure with manager & 3.20 & 0.60 & -0.12 & $0.48^{\star \star}$ & $0.72^{\star \star}$ & - & & & & & & \\
\hline 5. PTL & 3.61 & 0.80 & 0.03 & -0.04 & -0.10 & -0.03 & $(0.94)$ & & & & & \\
\hline 6. Extraversion & 3.49 & 0.80 & $-0.15^{\star}$ & 0.00 & 0.04 & 0.08 & 0.08 & $(0.86)$ & & & & \\
\hline 7. Conscientiousness & 4.05 & 0.70 & -0.05 & -0.05 & -0.08 & -0.05 & 0.08 & $0.23^{\star \star}$ & $(0.80)$ & & & \\
\hline 8. Agreeableness & 3.49 & 0.50 & 0.06 & -0.07 & -0.08 & -0.01 & 0.13 & 0.11 & $0.34^{\star \star}$ & $(0.72)$ & & \\
\hline 9. Neuroticism & 2.62 & 0.70 & -0.11 & $-0.15^{\star}$ & 0.05 & -0.07 & -0.01 & $-0.19 \star \star$ & $-0.20 \star \star$ & 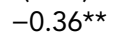 & $(0.80)$ & \\
\hline 10. JS & 3.76 & 0.60 & 0.06 & 0.07 & 0.02 & 0.13 & $0.51^{\star \star}$ & 0.05 & $0.21 \star \star$ & 0.09 & $-0.14^{\star}$ & $(0.85)$ \\
\hline
\end{tabular}

\section{Note. $N=221$}

Gender is coded as $0=$ woman, $1=$ man.

Cronbach's $\alpha$ coefficients are in parentheses in the diagonal.

$\mathrm{JS}=$ job satisfaction; $\mathrm{PTL}=$ perceived transformational leadership.

* $p<.05,{ }^{* \star} p<.001$. 
Perceived transformational leadership, job satisfaction

Table 3. Hierarchical regression analysis for predicting job satisfaction

\begin{tabular}{lcccc}
\hline \hline Predictors & $\beta$ & $R^{2}$ & Change in $R^{2}$ & $F$ \\
\hline Step 1 & & 0.30 & - & $18,54^{\star \star}$ \\
PTL & $0.35^{\star \star}$ & & & \\
Extraversion & -0.05 & & & \\
Agreeableness & 0.07 & & 0.03 & $11,74^{\star \star}$ \\
Conscientiousness & $0.18^{\star \star}$ & & & \\
Neuroticism & $-0.13^{\star}$ & & & \\
Step 2 & & 0.33 & & \\
PTL & $0.51^{\star \star}$ & & & \\
Extraversion & -0.03 & & & \\
Conscientiousness & $0.15^{\star}$ & & & \\
Agreeableness & 0.05 & & \\
Neuroticism & $-0.13^{\star}$ & & \\
PTL $\times$ extraversion & -0.08 & & \\
PTL $\times$ conscientiousness & $0.17^{\star}$ & & \\
PTL $\times$ agreeableness & -0.05 & & \\
PTL $\times$ neuroticism & -0.07 & & \\
\hline
\end{tabular}

Note. $N=221$.

$\mathrm{PTL}=$ perceived transformational leadership.

${ }^{*} p<.05,{ }^{* *} p<.01$.

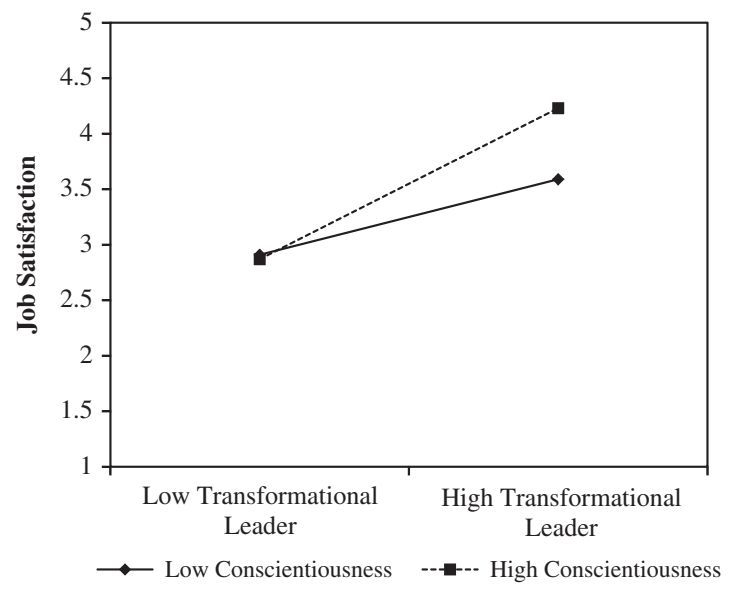

Figure 2. The interactive influence of perceived TL and conscientiousness on job satisfaction

leadership $\times$ conscientiousness $(\beta=0.172, p<.05)$ was statistically significant. This result supports Hypothesis 3, regarding the moderating effect of conscientiousness on the relationship between transformational leadership and job satisfaction. However, contrary to the predictions of Hypotheses 2, 4 and 5, the moderating effects of neuroticism, extraversion and agreeableness, respectively, on the transformational leadership-job satisfaction linkage were not supported.

In order to illustrate the interaction effect, we plotted the regression of the dependent variable on the independent variable by taking $1 \mathrm{SD}$ above and 1 SD below the mean of the moderating variable, as Cohen et al. (2003) recommend. Figure 2 shows how the relationship between transformational leadership and job satisfaction varies as a function of the conscientiousness trait. A simple slope for the 
association between transformational leadership and job satisfaction was also tested for low, moderate and high levels of conscientiousness. Simple slope revealed a positive association for moderate $(t=7.82, p<.00)$ and high levels of conscientiousness $(t=6.45, p<.00)$. That is, the form of the moderating effect is consistent with Hypothesis 3, such that the more conscientious the individual, the stronger the relationship between perceived transformational leadership and job satisfaction.

\section{STUDY 2}

As noted earlier, Study 2 provides an examination regarding the mediating role of psychological empowerment on the relationship between perceived transformational leadership and job satisfaction. In this respect, the study looks beyond the dispositional characteristics investigated in the first study and explores the underlying processes by which followers' perceptions of their leaders as more transformational precipitate influence on job satisfaction.

\section{Study 2 method}

\section{Participants}

The participants for Study 2 were 348 academics working in the engineering departments of three universities in Ankara, Turkey. These departments undertake technological projects and allow opportunities for managing knowledge work, displaying innovative and creative behaviours and thus selfimprovement, all of which reinforce the relevant factors of transformational leadership and psychological empowerment in organizations (Garcia-Morales, Jiménez-Barrionuevo, \& Gutiérrez-Gutiérrez, 2012).

Of the respondents, 216 were male $(62.24 \%)$ and 131 female $(37.8 \%)$, with an average age of 37.8 and an organizational tenure of 5.7 years. One participant did not provide gender information.

\section{Measures}

Multifactor Leadership Questionnaire. In accordance with Study 1, we used the same Multifactor Leadership Questionnaire (Form 5X-Short) (Bass \& Avolio, 1995) in Study 2. We found the Cronbach's $\alpha$ reliability coefficient of the scale to be 0.93 .

Psychological empowerment scale. Followers' psychological empowerment perceptions were assessed using Spreitzer's (1995) psychological empowerment scale. For each of the four psychological empowerment components (meaning, competence, self-determination and impact), the scale contains three items, for a total of 12 items. Sample items are as follows: 'The work I do is meaningful to me' and 'I have mastered the skills necessary for my job'. Participants were asked to evaluate each item by providing five alternatives, scoring from $1=$ 'strongly disagree,' to $5=$ 'strongly agree'. Higher scores specify the perception of being more psychologically empowered. Since the psychological empowerment dimensions combine to provide a total empowerment score (Spreitzer, 1995), we used an overall measure of psychological empowerment in our analyses. The Turkish adaptation of the instrument was borrowed from Ergeneli, Saglam Ari, and Metin (2007). The Cronbach's $\alpha$ coefficient was 0.85.

Job satisfaction. As in Study 1, the 20-item short form of the Minnesota Satisfaction Questionnaire (MSQ) was used to assess employee satisfaction. Cronbach's $\alpha$ coefficient was found to be 0.89 .

BFI. As in Study 1, employee's personality traits were measured with the 44-item BFI developed by John, Donahue, and Kentle (1991). Cronbach's $\alpha$ coefficients for each personality trait was found to 
be satisfactory $(\alpha=0.76$ for extroversion; $\alpha=-0.79$ for conscientiousness; $\alpha=0.70$ for agreeableness; $\alpha=0.76$ for neuroticism; $\alpha=0.80$ for openness to experience.

\section{Procedure}

All the data were collected and administered on site during work time. Questionnaires were distributed to participants on convenience method, meaning that only academics who were in their offices when the questionnaires were distributed took part in the study. When the aim of the study was introduced, confidentiality and anonymity were assured, and informed consent was obtained from all participants. No incentives were offered. Out of the 450 questionnaires distributed, 348 questionnaires were returned, for a response rate of $77.3 \%$.

As the data for Study 2 were collected from a single source, we again performed Harman's singlefactor test, examining the unrotated factor solution to determine the number of factors that accounted for the variance in the variables (Podsakoff et al., 2003). Principal component analysis produced nine factors, with the first factor explaining $27.8 \%$ of the variances. This result gives confidence that no single factor accounted for a majority of the covariance and no general factor was apparent, suggesting that common method variance is not a serious issue in this study (Podsakoff \& Organ, 1986). As in Study 1, we made common method factor model test to verify the results of Harman's single factor test. The addition of common method factor to the measurement model deteoriated the model fit $\left(\Delta \chi^{2}[d f=63]=1,365.3 ; p<.05\right)$. Except for one job satisfaction item, all of the standardized factor loadings were found to be significant in both with and without common factor models. These results together with the results of Harman's single factor test suggested that common method variance problem was not a serious factor for this study.

\section{Study 2 results}

\section{Preliminary analysis}

As in Study 1, we performed a series of CFA to check the existence of discriminant validity and to verify whether items were able to measure the constructs that they had been supposed to measure. Normality and outlier analyses did not reveal any problems. After this initial data screening, we compared four measurement models listed in Table 4. All of the study variables were assumed to reflect independent constructs in the eight-factor model. In the four-factor model, five personality factors were combined into one factor; the remaining variables were assumed to be independent factors. In the second-factor model, five personality factors and other three variables (i.e., job satisfaction and perceived transformational leadership) were assumed to measure two independent factors and lastly in the one-factor model, all variables were bound into one overall factor.

Table 4. Comparison of measurement models for main variables in Study 2

\begin{tabular}{llllll}
\hline \hline Models & Factors & $\chi^{2} / d f$ & CFI & RMSEA & AIC \\
\hline 8 factor & PTL, JS, Emp, Ext, Cons, Agr, Ne, OE & 2.18 & 0.901 & 0.06 & $10,122.91$ \\
4 factor & PTL, JS, Emp, Ext + Cons + Agr + Ne+ OE & 2.75 & 0.707 & 0.07 & $12,684.57$ \\
2 factor & PTL + JS + Emp, Ext + Cons + Agr + Ne+ OE & 3.12 & 0.71 & 0.08 & $14,312.00$ \\
1 factor & PTL + JS + Emp + Ext + Cons + Agr + Ne + OE & 3.44 & 0.61 & 0.09 & $15,769.04$ \\
\hline \hline
\end{tabular}

Note. Agr = agreeableness; $\mathrm{AIC}=$ Akaike information criterion; $\mathrm{CFI}=$ comparative fit index; Cons = conscientiousness; $\mathrm{Emp}=$ empowerment; Ext = extroversion; JS = job satisfaction; $\mathrm{Ne}=$ neuroticism; $\mathrm{OE}=$ openness to Experience; PTL = perceived transformational leadership; RMSEA = root mean square error of approximation. 
As it can be seen from model fit indices in Table 4, four-, two- and one-factor models exhibited poorer fit than the eight-factor model. Comparison of alternative models with the Akaike information criterion again supported the superiority of seven-factor model (Akaike information criterion of sevenfactor model was found to be smaller in seven-factor model compared with alternative models). Comparison of different measurement models revealed that the variance among different variables was not same, suggesting the existence of discriminant validity among study variables.

The closer examination of modification indices and standardized factor loadings of eight-factor model suggested the existence of some problems. The standardized factor loading of one job satisfaction item (i.e., item 8) was lower than the threshold value of 0.40 and some error covariance terms were found to be correlated. Considering the independency of factors principle, we decided to add error covariance terms between some items (i.e., between perceived transformational leadership items between 1 and 2 and between transformational leadership items between 13 and 14). After the modifications, the model improved and supported a acceptable fit $\left(\chi^{2}[4,448]=9,605.36 ; p<.001 ; \chi^{2} / d f=2.16\right.$; goodness of fit index $(\mathrm{GFI})=0.90$; confirmatory fit index $(\mathrm{CFI})=0.89$; and root mean square error approximation $($ RMSEA $)=0.06$ ). Since all of the factor loadings were found to be significant, the scores of each study variable were calculated by taking the average of the scale items. However, as indicated before, one job satisfaction item was not taken into consideration when calculation job satisfaction scores of employees. As in Study 1, the composite score for openness to experience was not calculated.

Descriptive statistics. Means, standard deviations and intercorrelations among the variables are presented in Table 5. The correlations between variables provide initial support for our hypotheses, such that perceived transformational leadership is positively correlated with job satisfaction $(r=0.530$, $p<.01)$ and with psychological empowerment $(r=0.153, p<.01)$. Moreover, psychological empowerment is positively correlated with job satisfaction $(r=0.459, p<.01)$. As the demographic variables did not significantly correlate with the outcome variable of job satisfaction, we rendered them as control variables.

\section{Hypotheses testing for the mediating effect of psychological empowerment}

The hypothesized relationships were tested by Hayes and Preacher's (2014) mediation procedure. The analysis was run for job satisfaction as the dependent variable, perceived transformational leadership as the independent variable and psychological empowerment as the mediator. Table 6 shows the $\beta$ coefficients for the direct and indirect effects and bootstrap confidence intervals.

As Table 6 shows, a significant positive association is observed between employee perceptions of transformational leadership and job satisfaction $(\beta=0.35, p<.05)$, supporting Hypothesis 1 . Moreover, a significant indirect effect of transformational leadership perceptions on followers' job satisfaction through psychological empowerment was also observed $(\beta=0.06,95 \%$ bootstrap confidence interval $=0.03-0.09 ; R^{2}$ effect size $=0.09$ ), providing support for Hypothesis 5 . The Sobel test was also significant $(z=3.95, p<.01)$, which illustrates that psychological empowerment acts as a mediator between perceived transformational leadership and job satisfaction. That is, when employees perceive their leader as transformational, they feel more psychologically empowered, which increases their job satisfaction levels.

Using the data collected about personality traits, we combined the moderation model tested in Study 1 and mediation model tested in Study 2. Accordingly, we tested the moderating effect of personality traits on the mediated model in which empowerment mediates the relationship between perceived transformational leadership and job satisfaction. Using the model 59 specified in the Process macro (Hayes, 2013), we tested whether personality traits moderate the relationship between (1) transformational leadership and psychological empowerment; (2) psychological empowerment and 
Table 5. Descriptive statistics, $\alpha$ coefficients and correlations among Study 2 variables

\begin{tabular}{|c|c|c|c|c|c|c|c|c|c|c|c|c|c|}
\hline Variables & Mean & $S D$ & 1 & 2 & 3 & 4 & 5 & 6 & 7 & 8 & 9 & 10 & 11 \\
\hline 1. Gender & - & & - & & & & & & & & & & \\
\hline 2. Age & 37.80 & 4.12 & $-0.14^{\star \star}$ & - & & & & & & & & & \\
\hline 3. Job tenure & 5.70 & 0.91 & $-0.21 \star \star$ & $0.54^{\star \star}$ & - & & & & & & & & \\
\hline 4. Tenure with manager & 3.10 & 0.50 & $-0.13^{\star}$ & $0.43^{\star \star}$ & $0.69 * \star$ & - & & & & & & & \\
\hline 5. PTL & 3.57 & 0.79 & -0.03 & 0.01 & -0.09 & -0.05 & $(0.93)$ & & & & & & \\
\hline 6. $\mathrm{PE}$ & 4.01 & 0.61 & $0.13^{*}$ & $0.12^{\star}$ & $0.13^{\star}$ & $0.14^{*}$ & $0.24^{\star \star}$ & $(0.85)$ & & & & & \\
\hline 7. Ext & 3.55 & 0.70 & -0.08 & 0.01 & 0.03 & -0.02 & $0.13^{\star}$ & 0.30 ** & $(0.76)$ & & & & \\
\hline 8. Cons & 3.10 & 0.70 & -0.05 & -0.06 & -0.05 & -0.03 & $0.12^{\star}$ & $0.37^{\star \star}$ & $0.36^{\star \star}$ & (0.79) & & & \\
\hline 9. Agr & 3.90 & 0.56 & -0.07 & 0.01 & -0.01 & 0.03 & $0.17^{\star \star}$ & $0.29 * *$ & 0.30 ** & $0.52^{\star \star}$ & $(0.70)$ & & \\
\hline 10. $\mathrm{Ne}$ & 2.55 & 0.72 & $-0.11^{\star}$ & -0.06 & 0.07 & -0.03 & -0.08 & $-0.26^{\star \star}$ & $-0.29 \star \star$ & $-0.36^{\star \star}$ & $-0.45^{\star \star}$ & $(0.76)$ & \\
\hline 11. JS & 3.70 & 0.62 & -0.02 & 0.13 & 0.03 & 0.12 & $0.53^{\star \star}$ & $0.46^{\star \star}$ & $0.12^{\star}$ & $0.21^{\star \star}$ & 0.19 ** & $-0.12^{\star}$ & $(0.89)$ \\
\hline
\end{tabular}

Note. $N=348$.

Gender is coded as $0=$ woman, $1=$ man.

Cronbach's $\alpha$ coefficients are in parentheses in the diagonal.

Agr = agreeableness; Cons $=$ Conscientiousness; Ext $=$ extroversion; JS $=$ job satisfaction; $\mathrm{Ne}=\mathrm{Neuroticism;} \mathrm{PE}=$ psychological empowerment; PTL $=$ perceived transformational leadership.

${ }^{*} p<.05,{ }^{* *} p<.001$ 
TABLe 6. Results of the mediation analysis

\begin{tabular}{|c|c|c|c|c|}
\hline Model summary $(D V=P E)$ & & $R^{2}$ & $F$ & $p$ \\
\hline $\begin{array}{l}\text { Variables } \\
\text { PTL }\end{array}$ & $\begin{array}{c}\text { Coefficient } \\
0.18^{\star \star}\end{array}$ & $\begin{array}{l}0.05 \\
\text { SE } \\
0.04\end{array}$ & $\begin{array}{c}20.67 \\
t \\
4.54\end{array}$ & $\begin{array}{l}0 \\
p \\
0\end{array}$ \\
\hline Model summary $(D V=J S)$ & & $R^{2}$ & $F$ & $p$ \\
\hline $\begin{array}{l}\text { Variables } \\
\text { PE } \\
\text { PTL }\end{array}$ & $\begin{array}{c}\text { Coefficient } \\
0.36^{\star \star} \\
0.35^{\star \star}\end{array}$ & $\begin{array}{c}0.40 \\
\text { SE } \\
0.04 \\
0.03\end{array}$ & $\begin{array}{c}114.63 \\
t \\
8.22 \\
10.39\end{array}$ & $\begin{array}{l}0 \\
p \\
0 \\
0\end{array}$ \\
\hline \multirow[t]{2}{*}{ Direct effect of PTL on JS } & Effect & SE & $t$ & $p$ \\
\hline & $0.35^{\star \star}$ & 0.03 & 10.39 & 0 \\
\hline \multirow[t]{2}{*}{ Indirect effect through mediator } & Effect & Boot SE & Boot LLCI & Boot ULCI \\
\hline & $0.07 \star$ & 0.02 & 0.04 & 0.09 \\
\hline
\end{tabular}

Note. $\mathrm{N}=348$.

$\mathrm{DV}=$ dependent variable; $\mathrm{JS}=$ job satisfaction; $\mathrm{PE}=$ psychological empowerment $; \mathrm{PTL}=$ perceived transformational leadership; $\mathrm{LLCl}=$ lower limit of confidence interval; $\mathrm{ULCl}=$ upper limit of confidence interval.

${ }^{\star} p<.05,{ }^{\star *} p<.00$.

job satisfaction; and (3) perceived transformational leadership and job satisfaction. Except conscientiousness, none of the personality variables moderated the aforementioned relations. The moderating effect of conscientiousness on the linkage between perceived transformational leadership and job satisfaction was found to be significant $(\beta=0.21 ; t=2.20 ; p=.04)$. This finding seems to be in line with the findings obtained in Study 1 such that perceived transformational leadership seems to have stronger positive relationships with job satisfaction among employees high in conscientiousness.

\section{GENERAL DISCUSSION}

The purpose of this research is to enhance the understanding of the link between perceived transformational leadership and job satisfaction by focussing on followers' personality traits and followers' psychological empowerment. Our findings concerning both studies suggest three main conclusions. First, consistent with previous studies (Podsakoff, MacKenzie, Moorman, \& Fetter, 1990; Piccolo \& Colquitt, 2006; Braun et al., 2013), we find a positive direct (Study 1) and indirect association (Study 2) between perceived transformational leadership and job satisfaction. That is, perceived transformational leadership serves as an informative framework in examining the predictors of job satisfaction. This finding suggests that when employees regard their leaders as more transformational they become more satisfied with their jobs. Since transformational leaders motivate their followers to perform beyond expectations (Keegan \& Hartog, 2004) and transmit a sense of mission and intellectual stimulation (Bass, 1985) it seems reasonable that perceived transformational leadership could intrinsically foster more job satisfaction.

Second, as an important contribution to the literature, we tested the moderating roles of followers' personality traits on the relationship between perceived transformational leadership and job satisfaction by 
focussing on a follower-centred perspective. The results of Study 1 provide evidence for the moderating effects of conscientiousness on the perceived transformational leadership-job satisfaction linkage. That is, perceived transformational leadership consistently yields stronger positive relationships with job satisfaction among employees high in conscientiousness compared with employees low in conscientiousness. This finding is partly in line with researchers (Howell, Dorfman, \& Kerr, 1986; Shamir, House, \& Arthur, 1993; Epitropaki \& Martin, 2005) who argue that followers' personality traits may moderate the relationship between TL behaviours and organizational outcomes. A possible explanation for the moderating effect of conscientiousness on the perceived TL-job satisfaction linkage might be attributed to specific forms of self-fulfilling prophecies, such as the Pygmalion and Galatea effects. 'The Pygmalion effect is a type of self-fulfilling prophecy in which raising manager expectations regarding subordinate performance boosts subordinate performance' (Eden, 1992: 271). That is, when leaders communicate high expectations to their followers, the followers may expect high expectations from themselves and perform much better. The Galatea effect is a self-driven phenomenon where individuals' own opinions about their abilities and self-worth ideas influence their performance. It assumes that when followers expect more of themselves, these expectations will in turn enhance their performance (Eden, 1992). In the Pygmalion effect, followers work towards meeting the expectations that are set by their leaders, whereas in the Galatea effect an individual sets expectations for himself or herself and strives to live up to them. As individuals who are high in conscientiousness have a tendency to attain more challenging goals that are set by leaders, it seems reasonable that Pygmalion effect might increase the strength of the relationship between perceived TL and job satisfaction specifically for conscientious followers.

High conscientious followers exhibit higher levels of sustained effort, which in turn may lead them to perform better. When such followers perceive their leaders' behaviours as transformational, because of the Galatea effect, their expectations of themselves may increase, they may perform better and at the end feel relatively higher job satisfaction. However, one should be cautious about this kind of inference, as our study did not assess but merely suggests possible Galatea and Pygmalion effects.

Contrary to our initial expectations, we failed to find any significant moderating effects of extraversion, agreeableness and neuroticism on the relationship between perceived transformational leadership and job satisfaction. To author's knowledge, as there has been no research exploring the possible moderating effects of personality traits on the stated relationship, we believe that this finding is an important contribution to the literature. Alternatively, apart from followers' personality traits, other factors might interact with perceived transformational leadership in its relationship with job satisfaction. In this respect, individuals' cultural value dimensions might be an intriguing factor. Some scholars argue that followers' responses to transformational leadership and how transformational leadership affects work-related attitudes may not be consistent across cultures (Bass 1997; Ergeneli, Gohar, \& Temirbekova, 2007). There exists evidence that collectivistic culture orientations influence perceived transformational leadership and work-related outcomes (Walumbwa \& Lawler, 2003). Thus, the collectivistic culture of Turkish followers (Hofstede, 1980) might lead them to expect their leaders to exhibit transformational leadership behaviours (Bass, 1995), and such followers might readily respond to transformational leadership practices (Gumusluoglu \& Ilsev, 2009). So, apart from personality characteristics, one might argue that cultural value orientations might cause followers to perceive their managers as more or less transformational.

Although not directly hypothesized, concerning the direct effects of personality traits on job satisfaction, we found a positive relationship for conscientiousness and a negative relationship for neuroticism in line with other studies made in Turkey (Camgoz \& Karapinar, 2011; Gümüşsoy, 2016). More specifically, congruent with prior research, our findings demonstrate that individuals who are high in conscientiousness report higher levels of job satisfaction (Winkelmann \& Winkelmann, 2008; Templer, 2012), whereas individuals who are high in neuroticism report lower levels of job satisfaction (Connolly \& Viswesvaran, 2000; Judge, Heller, \& Mount, 2002; Kim \& Chung, 2014). 
The third conclusion of this research pertains to the findings of Study 2. In exploring the 'black box' of how perceived transformational leadership influences job satisfaction (Avolio et al., 2004), we demonstrate that feelings of psychological empowerment mediate the relationship between perceived transformational leadership and job satisfaction. Based on the current sample of engineering academics, the results suggest that psychological empowerment partially mediates the relationship between perceived transformational leadership and job satisfaction. The findings imply that psychological empowerment is an important mechanism through which perceived transformational leadership exerts its effect on job satisfaction. That is, when followers perceive their leader as more transformational, they feel more psychologically empowered, which in turn contributes to increased levels of job satisfaction. This finding provides support to Bass's (1999) argument that transformational leadership may act through psychological empowerment in influencing work outcomes. Further, our findings confirm previous research (Fuller, Morrison, Jones, Bridger, \& Brown, 1999; Hechanova, Alampay, \& Franco, 2006; Wang \& Lee, 2009) and also the studies made in Turkey (Gürbüz, 2009; Bitmiş \& Ergeneli, 2011; Pelit, Öztürk, \& Arslantürk, 2011) demonstrating that empowered followers are likely to have higher levels of job satisfaction.

\section{Limitations and future research}

This study is not without its limitations. The first concerns the use of a cross-sectional design, which does not allow for an assessment of causality. Further research using longitudinal designs might infer the causality of the relationships studied here. Second, this paper relies on data collected from academics and white-collar employees working in R\&D at various information technology companies therefore participants are highly educated. It is possible that differences emanating from occupational classification (white/blue collar) and/or organizational culture or even national culture might affect the results. Especially, the unique characteristics of the academic sample (i.e., Study 2) need special consideration. The results reported in Study 2 might be affected by the fact that academics have a lot of autonomy in scheduling and handling their work, and often do not identify their supervisor as a specific leader. Therefore, it is noteworthy to mention that a more diverse sample may provide a different pattern or at least magnitude of results regarding the mediating role of empowerment. Replicating the study with a more heterogeneous sample in different organizations and cultures might increase the generalizability of future research. Third, as the data were collected from a single source (i.e., followers), there might be a potential threat for common method variance. Although several remedies were taken to reduce it (both Harman's test and CFA indicated the existence of separate constructs), future studies could validate selfreported data on transformational leadership with other sources, such as employee-leader dyads. Fourth, this study utilizes a perceived transformational leadership paradigm from the follower perspective; another avenue for research could consider the assumed similarity theory (Watson, Hubbard, \& Wiese, 2000), which argues the importance of the perceived similarity between the follower and the leader. Schyns and Felfe (2006) found that followers with similar characteristics to transformational leadership leaders perceive more transformational leadership behaviours in their leaders. Therefore, leaders' personalities could also be included into the model to test the assumed similarity effect and then explore its potential moderating effect on the relationship between transformational leadership and job satisfaction. Last but not least, further research might also explore other situational moderators (i.e., organizational climate, feedback environment) and their relationships with other outcome variables, such as organizational commitment.

\section{Practical implications}

There are several practical implications of the current research. In a broad sense, perceived transformational leadership is found to be positively associated with job satisfaction. Prior research has 
demonstrated that transformational leadership behaviours can be learned (Parry \& Sinha, 2005; Nielsen, Hrivnak, \& Shaw, 2009), and thus encouraging managers to adopt a transformational style in articulating a vision, inspiring employees, recognizing employees' needs and promoting creativity would likely then result in higher levels of job satisfaction.

The moderating role of followers' conscientiousness on the relationship between perceived transformational leadership and job satisfaction is the core finding of Study 1. That is, followers high in conscientiousness appraise their leaders as more transformational than those low in conscientiousness, and the former effect is more likely to increase job satisfaction. What implications do these findings hold for managers? For one, managers should acknowledge that to increase job satisfaction levels, emerging as and remaining an effective transformational leadership leader does not depend solely on their own behaviour but also on their followers' personalities (Felfe \& Schyns, 2010). That is, when managers express transformational leadership behaviours, it is important to understand that the same behaviour is interpreted differently among employees. Followers high in conscientiousness perceive higher transformational leadership characteristics than their counterparts, and this manifests in higher job satisfaction. Understanding the personality differences of their followers would appear to be a good way for managers to analyse and understand follower feedback, and then behave accordingly. Managers should not hesitate to discuss evaluations of their leadership practices with their followers; in this way, they can gain a better understanding of their followers' perceptions. Nevertheless, managers should likely expect more support and commitment from conscientious followers.

The mediating role of followers' psychological empowerment between perceived transformational leadership and job satisfaction is the core finding of Study 2. That is, by creating a greater sense of empowerment, one can inspire, albeit indirectly, higher levels of job satisfaction. Managers who wish to enhance their followers' job satisfaction should be aware and capable of increasing followers' psychological empowerment by fostering goal internalization, creating a sense of choice and impact, and making followers feel that they have some choice in their work lives. Moreover, how managers demonstrate transformational types of leadership behaviours highly affects psychological empowerment feelings. For instance, by helping employees to become more innovative and creative, managers may engender feelings of competence. Additionally, by creating opportunities for followers to make changes in their own work, managers may increase employees' feelings of impact and choice (Rafferty \& Griffin, 2004). Further, managers could be more sensitive to followers' developmental needs and support and coach their followers, which may foster self-determination and impact, thereby result in more intrinsic job satisfaction.

\section{Conclusion}

The aim of this paper is to investigate the moderating effects of personality traits (i.e., extraversion, conscientiousness, agreeableness and neuroticism) and the mediating effect of psychological empowerment on the relationship between perceived transformational leadership and job satisfaction. Although much progress has been made in how perceived transformation leadership affects employees' attitudes towards their job, studies addressing the moderating and mediating effects on transformational leader-follower attitudes linkage are relatively rare. Understanding the moderating effects of followers' personality traits may enhance the understanding of the dispositional predictors of job satisfaction, which would be helpful for devising proper employee selection, training and development programs. Furthermore, by demonstrating the key role of empowerment on perceived transformational leadership and job satisfaction, this study hopefully draws attention to the positive effects of delegation and participative management. 


\section{ACKNOWLEDGEMENT}

This research received no specific grant from any funding agency, commercial, or not-for-profit sectors. All authors have read and approved the paper and have met the criteria for authorship listed above.

\section{Conflicts of Interest}

None.

\section{References}

Avolio, B. J. (1999). Full leadership development: Building vital forces in organizations. Thousand Oaks, CA: Sage.

Avolio, B. J., Bass, B. M., \& Jung, D. I. (1999). Re-examining the components of transformational and transactional leadership using the Multifactor Leadership Questionnaire. Journal of Occupational and Organizational Psychology, 72, 441-462.

Avolio, B. J., Zhu, W., Koh, W., \& Bhatia, P. (2004). Transformational leadership and organizational commitment: Mediating role of psychological empowerment and moderating role of structural distance. Journal of Organizational Behaviour, 25, 951-968.

Awamleh, R., \& Gardner, W. L. (1999). Perceptions of leader charisma and effectiveness: The effect of vision content, delivery, and organizational performance. Leadership Quarterly, 10(3), 345-373.

Aycan, Z. (2001). Human resource management in Turkey-current issues and future challenges. International Journal of Manpower, 22(3), 252-260.

Aycan, Z., \& Kanungo, R. N. (2000). Topolumsal kültürün kurumsal kültür ve insan kaynakları uygulamalari üzerine etkileri [Effects of social culture on organizational culture and human resources practices]. Management, Leadership, and Human Resources Practices in Turkey. Istanbul, Turkey: DETAM.

Aycan, Z., \& Fikret-Pasa, S. (2003). Career choices, job selection criteria, and leadership preferences in a transitional nation: The case of Turkey. Journal of Career Development, 30(2), 129-144.

Aycan, Z., Kanungo, R. N., Mendonca, M., Yu, K., Deller, J., Stahl, G., \& Khursid, A. (2000). Impact of culture on human resource management practices: A ten country comparison. Applied Psychology: An International Review, 49(1), 192-220.

Bartram, T., \& Casimir, G. (2006). The relationship between leadership and follower in-role performance and satisfaction with the leader. Leadership \& Organization Development Journal, 28(1), 4-19.

Bass, B. M. (1985). Leadership and performance beyond expectations. New York: The Free Press.

Bass, B. M. (1990). Bass and Stogdill's handbook of leadership. New York: Free Press.

Bass, B. M. (1995). Comment: Transformational leadership looking at other possible antecedents and consequences. Journal of Management Inquiry, 4(3), 293-298.

Bass, B. M. (1997). Does the transactional-transformational leadership paradigm transcend organizational and national boundaries? American Psychologist, 52(2), 130-139.

Bass, B. M. (1999). Two decades of research and development in transformational leadership. European Journal of Work and Organizational Psychology, 8, 9-32.

Bass, B. M., \& Avolio, B. J. (1994). Transformational leadership and organizational culture. The International Journal of Public Administration, 17(3-4), 541-554.

Bass, B. M., \& Avolio, B. J. (1995). Multifactor Leadership Questionnaire: Manual leader form, rater, and scoring key for MLQ (Form 5x-Short). Redwood City, CA: Mind Garden.

Bilgic, R. (1998). The relationship between job satisfaction and personal characteristics of Turkish workers. The Journal of Psychology, 132(5), 549-557.

Bitmiş, M. G., \& Ergeneli, A. (2011). Contingency approach to strategic management: A test of the mediating effect of leader member exchange on the relationship between psychological empowerment and job satisfaction in 21st century workplace. Procedia-Social and Behavioral Sciences, 24, 1143-1153.

Bodla, M. A., \& Hussain, G. (2010). Followers' characteristics and leadership styles: An empirical fit among employees of Pakistan. Journal of US-China Public Administration, 7(6), 73-81.

Bogler, R. (2001). The influence of leadership style on teacher job satisfaction. Educational Administration Quarterly, $37(5), 662-683$. 
Bono, J. E., Hooper, A. C., \& Yoon, D. J. (2012). Impact of rater personality on transformational and transactional leadership ratings. The Leadership Quarterly, 23(1), 132-145.

Braun, S., Peus, C., Weisweiler, S., \& Frey, D. (2013). Transformational leadership, job satisfaction, and team performance: A multilevel mediation model of trust. The Leadership Quarterly, 24(1), 270-283.

Burns, J. M. (1978). Leadership. New York: Harper \& Row.

Bycio, P., Hackett, R. D., \& Allen, J. S. (1995). Further assessments of Bass's (1985) conceptualization of transactional and transformational leadership. Journal of Applied Psychology, 80, 468-478.

Camgoz, S. M., \& Karapinar, P. B. (2011). Managing job satisfaction: The mediating effect of procedural fairness. International Journal of Business and Social Science, 2(8), 234-243.

Castro, B. C., Villegas, P. M. M., \& Casillas, B. J. C. (2008). Transformational leadership and followers' attitudes: The mediating role of psychological empowerment. The International Journal of Human Resource Management, 19(10), 1842-1863.

Christiansen, N., Sliter, M., \& Frost, C. T. (2014). What employees dislike about their jobs: Relationship between personality-based fit and work satisfaction. Personality and Individual Differences, 71, 25-29.

Cicero, L., \& Pierro, A. (2007). Charismatic leadership and organizational outcomes: The mediating role of employees' work-group identification. International Journal of Psychology, 42(5), 297-306.

Cohen, J., Cohen, P., West, S. G., \& Aiken, L. S. (2003). Applied multiple regression/correlation analysis for the behavioral sciences (3rd ed.), Mahwah, NJ: Lawrence Erlbaum Associates.

Conger, J. A., \& Kanungo, R. N. (1998). Charismatic leadership in organizations. Thousand Oaks, CA: Sage.

Conger, J. A., Kanungo, R. N., \& Menon, S. T. (2000). Charismatic leadership and follower effects. Journal of Organizational Behavior, 21(7), 747-767.

Connolly, J., \& Viswesvaran, C. (2000). The role of affectivity in job satisfaction: A meta-analysis. Personality and Individual Differences, 29, 265-281.

Cooper-Hakim, A., \& Viswesvaran, C. (2005). The construct of work commitment: Testing an integrative framework. Psychological Bulletin, 131(2), 241-259.

Çoğaltay, N., Yalcin, M., \& Karadağ, E. (2016). Educational leadership and job satisfaction of teachers: A meta-analysis study on the studies published between 2000 and 2016 in Turkey. Eurasian Journal of Educational Research, 62, 273-298.

DeNeve, K., \& Cooper, H. (1998). The happy personality: A meta-analysis of 137 personality traits and subjective well-being. Psychological Bulletin, 124(2), 197-229.

Dust, S. B., Resick, C. J., \& Mawritz, M. B. (2014). Transformational leadership, psychological empowerment, and the moderating role of mechanistic-organic contexts. Journal of Organizational Behavior, 35(3), 413-433.

Dvir, T., \& Shamir, B. (2003). Follower developmental characteristics as predicting transformational leadership: A longitudinal field study. Leadership Quarterly, 14, 327-344.

Eden, D. (1992). Leadership and expectations: Pygmalion effects and other self-fulfilling prophecies in organizations. Leadership Quarterly, 3, 271-305.

Ehrhart, M. G., \& Klein, K. J. (2001). Predicting followers' preferences for charismatic leadership: The influence of follower values and personality. The Leadership Quarterly, 12, 153-179.

Epitropaki, O., \& Martin, R. (2005). The moderating role of individual differences in the relation between transformational/transactional leadership perceptions and organizational identification. The Leadership Quarterly, 16(4), 569-589.

Ergeneli, A., Gohar, R., \& Temirbekova, Z. (2007). Transformational leadership: Its relationship to culture value dimensions. International Journal of Intercultural Relations, 31(6), 703-724.

Ergeneli, A., Saglam Ari, G., \& Metin, S. (2007). Psychological empowerment and its relationship to trust in immediate managers. Journal of Business Research, 60(1), 41-56.

Ettlie, J. E. (1983). Organizational policy and innovation among suppliers to food processing sector. Academy of Management Journal, 26(1), 27-44.

Eylon, D., \& Bamberger, P. (2000). Empowerment cognitions and empowerment acts: Recognizing the importance of gender. Group and Organization Management, 25, 354-372.

Felfe, J., \& Schyns, B. (2006). Personality and the perception of transformational leadership: The impact of extraversion, neuroticism, personal need for structure, and occupational self-efficacy. Journal of Applied Social Psychology, 36, 708-739. 
Felfe, J., \& Schyns, B. (2010). Followers' personality and the perception of transformational leadership: Further evidence for the similarity hypothesis. British Journal of Management, 21, 393-410.

Fikret-Pasa, S., Kabasakal, H., \& Bodur, M. (2001). Society, organizations, and leadership in Turkey. Applied Psychology: An International Review, 50(4), 559-589.

Fuller, J. B., Morrison, R., Jones, L., Bridger, D., \& Brown, V. (1999). The effects of psychological empowerment on transformational leadership and job satisfaction. The Journal of Social Psychology, 139(3), 389-391.

Furnham, A., Eracleous, A., \& Chamorro-Premuzic, T. (2009). Personality, motivation and job satisfaction: Hertzberg meets the big five. Journal of Managerial Psychology, 24(8), 765-779.

Garcia-Morales, V. J., Jiménez-Barrionuevo, M. M., \& Gutiérrez-Gutiérrez, L. (2012). Transformational leadership influence on organizational performance through organizational learning and innovation. Journal of Business Research, 65(7), 1040-1050.

Gardner, W. L., \& Avolio, B. J. (1998). The charismatic relationship: A dramaturgical perspective. Academy of Management Review, 23, 32-58.

Ghanbari, S., \& Eskandari, A. (2014). Transformational leadership, job satisfaction, and organizational innovation. International Journal of Management Perspective, 1(4), 81-94.

Goldberg, L. R. (1990). An alternative 'description of personality': The Big-Five factor structure. Journal of Personality and Social Psychology, 59, 1216-1229.

Goregenli, M. (1997). Individualist-collectivist tendencies in a Turkish sample. Journal of Cross-Cultural Psychology, 28(6), 787-794.

Gumusluoglu, L., \& Ilsev, A. (2009). Transformational leadership, creativity, and organizational innovation. Journal of Business Research, 62, 461-473.

Gumusluoglu, L., Karakitapoğlu-Aygün, Z., \& Hirst, G. (2013). Transformational leadership and R\&D workers' multiple commitments: Do justice and span of control matter? Journal of Business Research, 66(11), 2269-2278.

Gümüşsoy, Ç. A. (2016). The effect of five-factor model of personality traits on turnover intention among information technology (IT) professionals. Academic Journal of Information Technology, 74(22), 7-28.

Gürbüz, S. (2009). The effect of high performance HR practices on employees' job satisfaction. Istanbul University Journal of the School of Business Administration, 38(2), 110-123.

Hayes, A. F. (2013). Introduction to mediation, moderation, and conditional process analysis: A regression-based approach. New York: Guilford Press.

Hayes, A. F., \& Preacher, K. J. (2014). Statistical mediation analysis with a multicategorical independent variable. British Journal of Mathematical and Statistical Psychology, 67(3), 451-470.

Hechanova, M., Alampay, R., \& Franco, E. (2006). Psychological empowerment, job satisfaction, and performance among Filipino service workers. Asian Journal of Social Psychology, 9, 72-78.

Hetland, H., \& Sandal, G. (2003). Transformational leadership in Norway: Outcomes and personality correlates. European Journal of Work and Organizational Psychology, 12(2), 147-170.

Hetland, H., Sandal, G. M., \& Johnsen, T. B. (2008). Followers' personality and leadership. Journal of Leadership \& Organizational Studies, 14(4), 322-331.

Hofstede, G. (1980). Culture's consequences: International differences in work-related values. Beverly Hills, CA: Sage.

Howell, J. P., Dorfman, P. W., \& Kerr, S. (1986). Moderator variables in leadership research. Academy of Management Review, 11, 88-102.

Hsieh, J. Y. (2013). Impact of individual and organizational factors on job satisfaction: A comparison of multilevel models and multiple regression models using different data arrangements. Journal of Management \& Organization, 19(1), 44-59.

Hulin, C. L., \& Judge, T. A. (2003). Job attitudes. In W. C. Bornman \& D. R. Ilgen (Eds.), Handbook of psychology: Industrial and organizational psychology (pp. 255-276). New York: John Wiley \& Sons.

Hurtz, G. M., \& Donovan, J. J. (2000). Personality and job performance: The big five revisited. Journal of Applied Psychology, 85, 869-879.

John, O. P., Donahue, E. M., \& Kentle, R. L. (1991). The Big Five Inventory - Versions 4a and 54. Berkeley, CA: Institute of Personality and Social Research, University of California.

Joo, B. K. B., \& Lim, T. (2013). Transformational leadership and career satisfaction: The mediating role of psychological empowerment. Journal of Leadership \& Organizational Studies, 20(10), 1-11. 
Judge, T. A,.., \& Bono, J. E. (2000). Five-factor model of personality and transformational leadership. Journal of Applied Psychology, 85, 751-765.

Judge, T. A., Heller, D., \& Mount, M. K. (2002). Five-factor model of personality and job satisfaction: A meta-analysis. Journal of Applied Psychology, 87(3), 530-541.

Judge, T. A., Scott, B. A., \& Ilies, R. (2006). Hostility, job attitudes, and workplace deviance: Test of a multilevel model. Journal of Applied Psychology, 91, 126-138.

Jung, D. I., Chow, C., \& Wu, A. (2003). The role of transformational leadership in enhancing organizational innovation: Hypotheses and some preliminary findings. The Leadership Quarterly, 14(4), 525-544.

Jung, D. I., \& Sosik, J. J. (2002). Transformational leadership in work groups: The role of empowerment, cohesiveness and collective-efficacy on perceived group performance. Small Group Research, 33(3), 313-336.

Kabasakal, H., \& Bodur, M. (1998). Leadership, values and institutions: The case of Turkey. Research papers. Bogazici University, Istanbul, Turkey.

Kagitcibasi, C. (1996). Family and human development across cultures: A view from the other side. Mahwah, NJ: Lawrence Erlbaum Ass.

Kark, R., Shamir, B., \& Chen, G. (2003). The two faces of transformational leadership: Empowerment and dependency. Journal of Applied Psychology, 88, 246-255.

Keegan, A. E., \& Hartog, D. N. D. (2004). Transformational leadership in a project-based environment: A comparative study of the leadership styles of project managers and line managers. Project Management, 22, 609-617.

Keller, T. (1999). Images of the familiar: Individual differences and implicit leadership theories. Leadership Quarterly, $10,589-607$.

Kerfoot, K. (2001). From motivation to inspiration leadership. Nursing Economics, 19, 242-243.

Kim, H., \& Chung, Y. W. (2014). The use of social networking services and their relationship with the big five personality model and job satisfaction in Korea. Cyberpsychology, Behavior, and Social Networking, 17(10), 658-663.

Krishnan, V. R. (2012). Transformational leadership and personal outcomes: Empowerment as mediator. Leadership \& Organization Development Journal, 33(6), 550-563.

Locke, E. A. (1969). What is job satisfaction? Organizational Behavior and Human Performance, 4, 309-336.

Lord, R. G., DeVader, C. L., \& Alliger, G. M. (1986). A meta-analysis of the relation between personality traits and leadership perceptions: An application of validity generalization procedures. Journal of Applied Psychology, 71, 402-410.

Lowe, K. B., Kroeck, K. G., \& Sivasubramaniam, N. (1996). Effectiveness correlates of transformation and transactional leadership: A metaanalytic review of the MLQ literature. Leadership Quarterly, 7, 385-425.

Lucas, R. E., Diener, E., Grob, A., Suh, E. M., \& Shao, L. (2000). Cross-cultural evidence for the fundamental features of extraversion. Journal of Personality and Social Psychology, 79(3), 452-468.

Mardanov, I. T., Heischmidt, K., \& Henson, A. (2008). Leader-member exchange and job satisfaction bond and predicted employee turnover. Journal of Leadership and Organizational Studies, 15(2), 159-175.

McCrae, R. R., \& Costa, P. (1991). Adding Liebe und Arbeit: The full five-factor model and well-being. Journal of Personality and Social Psychology, 817(2), 227-232.

McCrae, R. R., \& Costa, P. T. (1997). Personality trait structure as a human universal. American Psychologist, 52(5), 509-516.

Monzani, L., Ripoll, P., \& Silla, J. M. P. (2014). Followers' agreeableness and extraversion and their loyalty towards authentic leadership. Psicothema, 26(1), 69-75.

Moss, S. A., \& Ngu, S. (2006). The relationship between personality and leadership preferences. Current Research in Social Psychology, 11(6), 70-91.

Nielsen, T. M., Hrivnak, G. A., \& Shaw, M. (2009). Organizational citizenship behavior and performance: A meta-analysis of group-level research. Small Group Research, 40, 1-23.

Organ, D. W., \& Lingl, A. (1995). Personality, satisfaction, and organizational citizenship behavior. Journal of Social Psychology, 135, 339-350.

Ozaralli, N. (2003). Effects of transformational leadership on empowerment and team effectiveness. Leadership \& Organization Development Journal, 24(6), 335-344.

Pai, A., \& Krishnan, V. R. (2015). Can transformational leadership increase the happiness index in organisations through empowerment? Journal of Organisation \& Human Behaviour, 2(3), 22-28.

Parmer, L., Green, M., Duncan, P., \& Zarate, C. (2013). The relationship between followers' personality and preferences in leadership. Journal of Leadership, Accountability and Ethics, 10(2), 55-64. 
Parry, K. W., \& Sinha, P. N. (2005). Researching the trainability of transformational organizational leadership. Human Resource Development International, 8(2), 165-183.

Pelit, E., Öztürk, Y., \& Arslantürk, Y. (2011). The effects of employee empowerment on employee job satisfaction: A study on hotels in Turkey. International Journal of Contemporary Hospitality Management, 23(6), 784-802.

Piccolo, R. F., \& Colquitt, J. A. (2006). Transformational leadership and job behaviors: The mediating role of core job characteristics. Academy of Management Journal, 49(2), 327-340.

Podsakoff, P. M., MacKenzie, S. B., Lee, J. Y., \& Podsakoff, N. P. (2003). Common method biases in behavioral research: A critical review of the literature and recommended remedies. Journal of Applied Psychology, 88(5), 879-903.

Podsakoff, P. M., MacKenzie, S. B., Moorman, R. H., \& Fetter, R. (1990). Transformational leader behaviors and their effects on followers' trust in leader satisfaction, and organizational citizenship behaviors. Leadership Quarterly, 1(2), 107-142.

Podsakoff, P. M., \& Organ, D. W. (1986). Self-reports in organizational research: Problems and prospects. Journal of Management, 12, 531-544.

Qu, R., Janssen, O., \& Shi, K. (2015). Transformational leadership and follower creativity: The mediating role of follower relational identification and the moderating role of leader creativity expectations. The Leadership Quarterly, 26(2), 286-299.

Rafferty, A. E., \& Griffin, M. A. (2004). Dimensions of transformational leadership: Conceptual and empirical extensions. The Leadership Quarterly, 15(3), 329-354.

Rusting, C. L., \& Larsen, R. J. (1997). Extraversion, neuroticism, and susceptibility to positive and negative affect: A test of two theoretical models. Personality and Individual Differences, 22(5), 607-612.

Salgado, J. F. (1997). The five factor model of personality and job performance in the European community. Journal of Applied Psychology, 82(1), 30-43.

Schyns, B., \& Felfe, J. (2006). The personality of followers and its effect on the perception of leadership an overview, a study, and a research agenda. Small Group Research, 37(5), 522-539.

Shamir, B., House, R. J., \& Arthur, M. B. (1993). The motivational effects of charismatic leadership: A self-concept based theory. Organization Science, 4(4), 577-594.

Slater, R. (2003). 29 Leadership secrets from Jack Welch. New York: McGraw Hill.

Spector, P. E. (1997). Job satisfaction: Application, assessment, causes, and consequences. Thousand Oaks, CA: Sage.

Spreitzer, G. M. (1995). Psychological empowerment in the workplace: Dimensions, measurement, and validation. Academy of Management Journal, 38(5), 1442-1465.

Sumer, N., Lajunen, T., \& Ozkan, T. (2005). Big five personality traits as the distal predictors of road accident involvement. In G. Underwood (Ed.), Traffic and transport psychology (pp. 215-227). Oxford: Elsevier Ltd.

Templer, K. J. (2012). Five-factor model of personality and job satisfaction: The importance of agreeableness in a tight and collectivistic Asian society. Applied Psychology: An International Review, 61(1), 114-129.

Tepper, B. J., \& Percy, P. M. (1994). Structural validity of the Multifactor Leadership Questionnaire. Educational and Psychological Measurement, 54, 734-744.

Thomas, K. W., \& Velthouse, B. A. (1990). Cognitive elements of empowerment: An interpretive model of intrinsic task motivation. Academy of Management Review, 15(4), 666-681.

Top, M., Tarcan, M., Tekingündüz, S., \& Hikmet, N. (2013). An analysis of relationships among transformational leadership, job satisfaction, organizational commitment and organizational trust in two Turkish hospitals. The International Journal of Health Planning and Management, 28(3), 217-241.

Walumbwa, F. O., \& Lawler, J. J. (2003). Building effective organizations: Transformational leadership, collectivist orientation, work-related attitudes, and withdrawal behaviors in three emerging economies. International Journal of Human Resource Management, 14(7), 1083-1101.

Walumbwa, F. O., Orwa, B., Wang, P., \& Lawler, J. J. (2005). Transformational leadership, organizational commitment, and job satisfaction: A comparative study of Kenyan and US financial firms. Human Resource Development Quarterly, 16(2), 235-256.

Wang, G., \& Lee, P. D. (2009). Psychological empowerment and job satisfaction: An analysis of interactive effects. Group \& Organization Management, 34(3), 1-26.

Watson, D., Hubbard, B., \& Wiese, D. (2000). General traits of personality and affectivity as predictors of satisfaction in intimate relationships: Evidence from self-and partner-ratings. Journal of Personality, 68(3), 413-449. 
Weiss, D. J., Dawis, R. V., England, G. W., \& Lofquist, L. H. (1967). Manual for the Minnesota satisfaction questionnaire. Minneapolis, MN: Minnesota Studies in Vocational Rehabilitation, University of Minnesota Industrial Relations Center.

Weiss, H. M., \& Cropanzano, R. (1996). Affective events theory: A theoretical discussion of the structure, causes and consequences of affective experiences at work. Staw, Barry M. (Ed); Cummings, L. L. (Ed). Research in Organizational Behavior, 18, 1-74.

Winkelmann, L., \& Winkelmann, R. (2008). Personality, work, and satisfaction: Evidence from the German socio-economic panel. The Journal of Positive Psychology, 3(4), 266-275.

Wofford, J. C., Whittington, J. L., \& Goodwin, V. L. (2001). Follower motive patterns as situational moderators for transformational leadership effectiveness. Journal of Managerial Issues, 13(2), 196-211.

Yammarino, F. J., Dubinsky, A. J., Comer, L. B., \& Jolson, M. A. (1997). Women and transformational and contingent reward leadership: A multiple-levels-of-analysis perspective. Academy of Management Journal, 4O(1), 205-222.

Yukl, G. A. (1994). Leadership in organizations. Englewood Cliffs, NJ: Prentice-Hall. 